\section{Laparoscopic Retrieval of a Needle Migrated from the Alimentary Tract}

Ingestion of foreign bodies is a common occurrence (1), and isolated cases of foreign bodies migrating through the walls of the alimentary tract have been reported $(1,2)$, for which exploratory laparotomy has been necessary. We report here a unique case in which laparoscopy was successfully used to retrieve such a foreign body that had migrated in this way.

A patient presented with epigastric pain after having ingested a sewing needle one month previously, which had been associated with an episode of melena. Sequential abdominal plain radio- graphs showed that the needle was lying anterior to the tip of the right transverse process of the twelfth thoracic vertebra. An upper gastrointestinal barium study showed that the needle was extraluminal, anterosuperior to the first part of the duodenum (Figure 1)

Laparoscopy was carried out with a 10-mm telescope, with two additional ports. Fibrous adhesions were seen between the first part of the duodenum and the falciform ligament. When these were dissected, the needle was visualized, impacted in the free border of the falciform ligament (Figure 2), and removed. The patient was discharged the following day. 


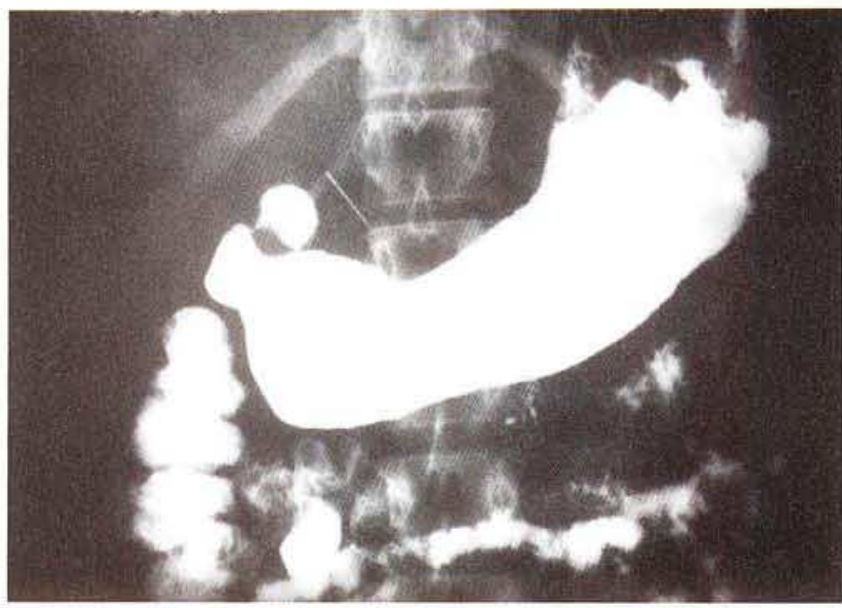

Figure 1: An upper gastrointestinal barium contrast study, showing the location of the sewing needle.

The removal of sharp foreign bodies is recommended, as there is a risk of abscess formation $(1,3)$, as well as migration to the heart, resulting in sudden death (4). Intrapelvic foreign bodies have been removed laparoscopically (4). Laparoscopic retrieval of a foreign body that had migrated from the alimentary tract has not been previously reported. Although laparoscopy has advantages over laparotomy (5), the limiting factor in laparoscopic foreign body retrieval has been the problem of localization, due to the absence of tactile sensations and a narrow field of vision. Once the foreign body has been located, removing it by withdrawing it into the cannula can be achieved safely. We offer this as a less invasive alternative to laparotomy when imaging studies suggest that the foreign body is capable of being located laparoscopically.

\section{H.K. Shah, S.R. Shah, M.D. Sanzgiri, S.K. Mathur}

Dept. of Surgery and Gastrointestinal Surgical Services, King Edward VII Memorial Hospital, Bombay, India

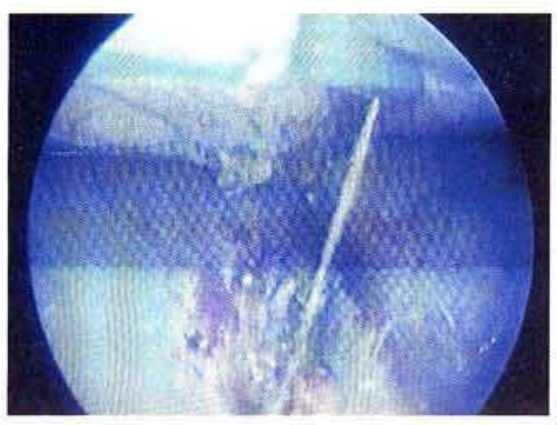

Figure 2: The needle impacted in the falciform ligament, as viewed with the la. paroscope.

\section{References}

1. Spitz L. Management of ingested foreign bodies in childhood. Br Med J 1971; 4: 469-72.

2. Abel RM, Fischer JE, Hendren WH. Penetration of the alimentary tract by a foreign body with migration to the liver. Arch Surg 1971; 102: 227-9.

3. Tristan TA, Daughtridge TG. Migration of a metallic pin from the humerus into the lung. N Engl J Med 1964: 270: 987-9.

4. Kottmeier S, Born CT, Saul H. Laparoscopic retrieval of a migrating intrapelvic pin: case report and review of the literature. J Trauma 1993; 35: $952-5$.

5. Levine RI. Economic impact of pelviscopic surgery. J Reprod Med 1985; 30: 655-9.

Corresponding Author

H. K. Shah, M.S.

5 A Sagar Tarang

132 Cadell Road

Mahim

Bombay 400016

India

Tel.: $+91-22-413-6051$ 